\title{
Strangulated obturator hernia: Report of 2 Cases
}

Nizar Kardoun ${ }^{1}$, Zied Hadrich ${ }^{2}$, Abderrahmen Masmoudi ${ }^{1}$, Houssem Harbi ${ }^{1}$, Salah Boujelben $^{1}$, and Rafik Mzali ${ }^{1}$

${ }^{1}$ Habib Bourguiba Hospital

${ }^{2}$ University of Sfax Faculty of Medecine of Sfax

May 14, 2021

\begin{abstract}
Obturator hernia is a rare condition. It is more commun in women than men owing to their greater width of the pelvis and larger obturator canal. We report 2 cases of strangulated obturator hernia, which were preoperatively diagnosed, in 2 female patients without previous history of abdominal surgery.
\end{abstract}

\section{Hosted file}

Strangulated obturator hernia.pdf available at https://authorea.com/users/412998/articles/ 522061-strangulated-obturator-hernia-report-of-2-cases
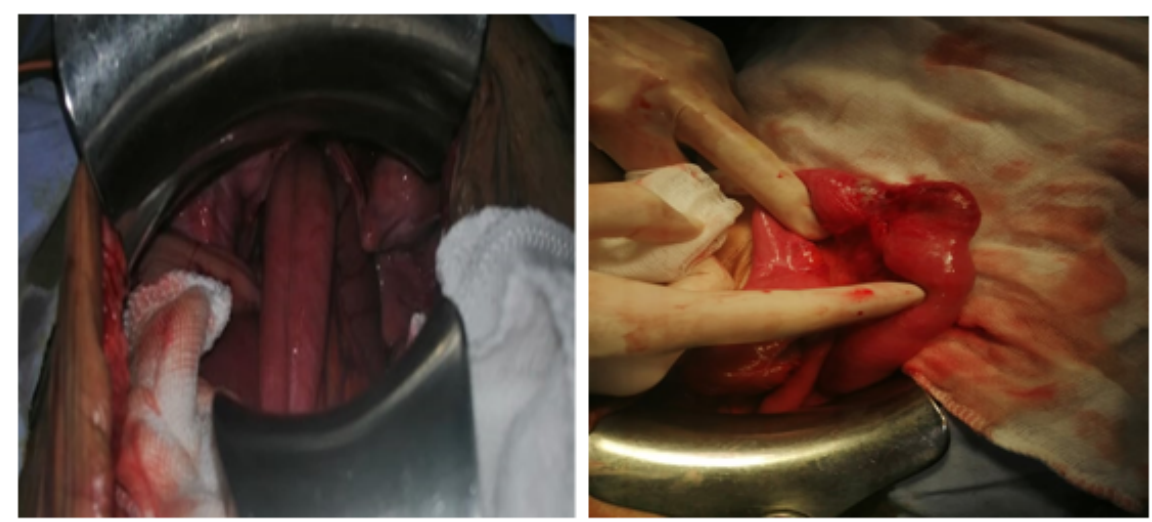

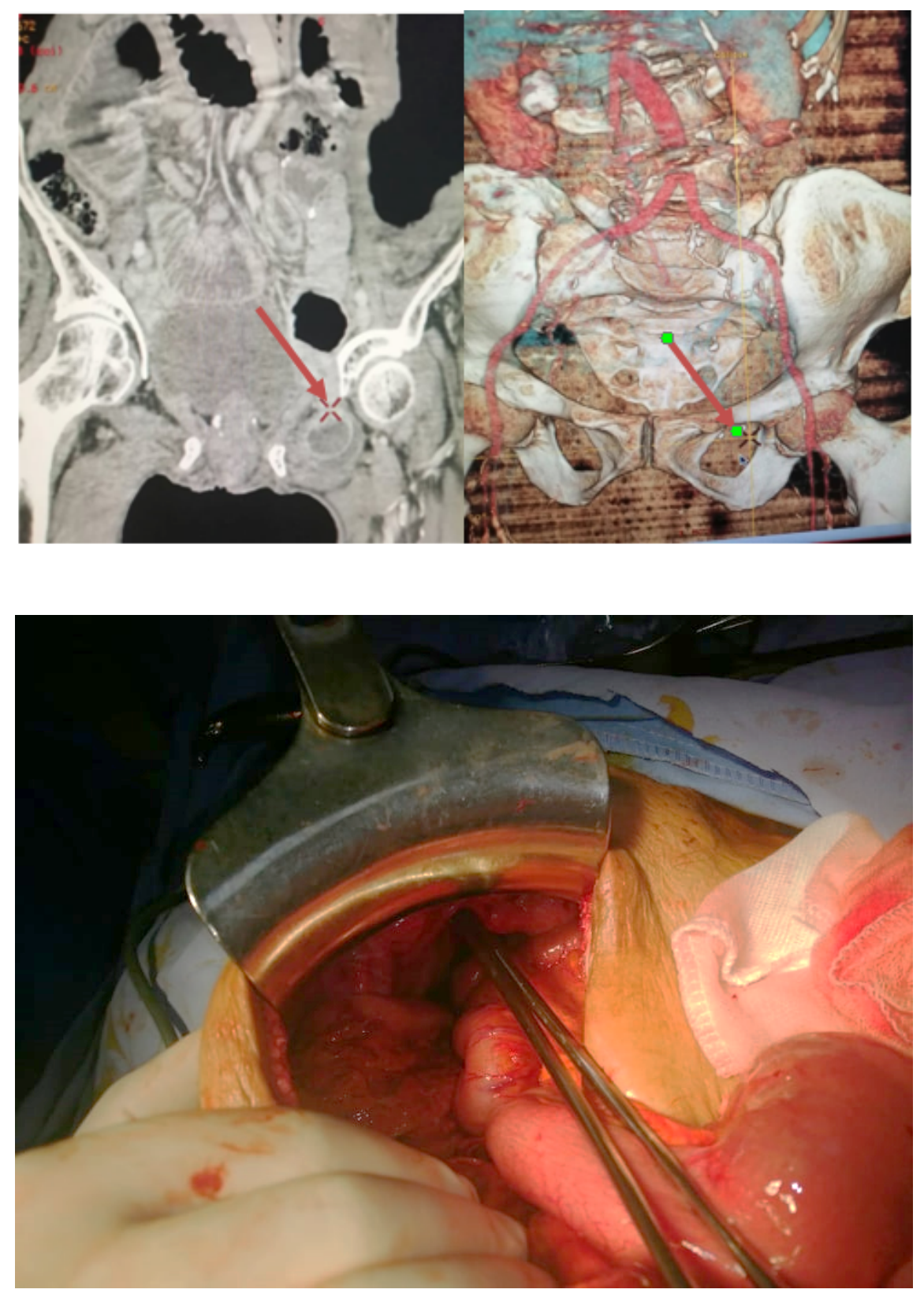


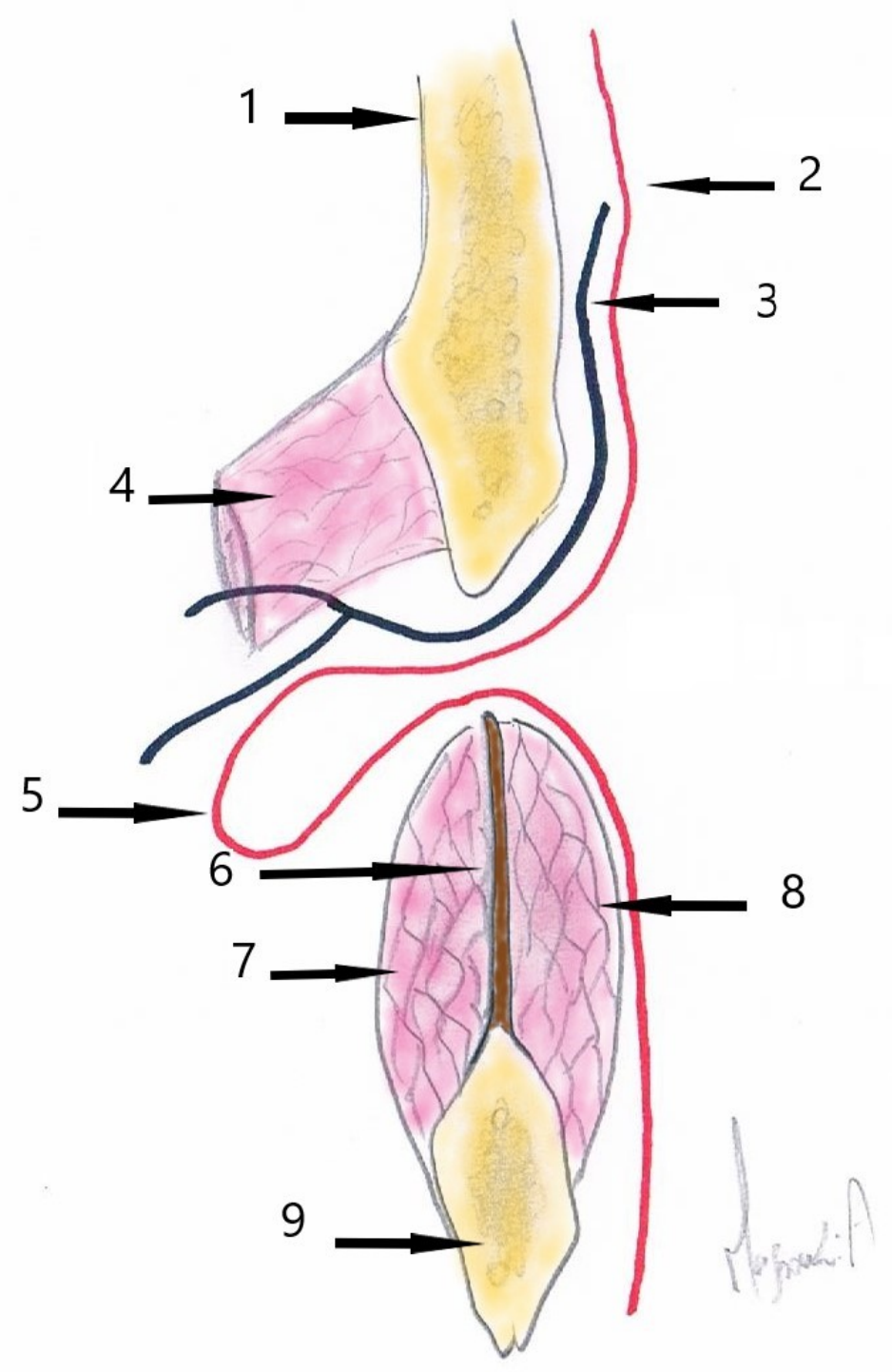




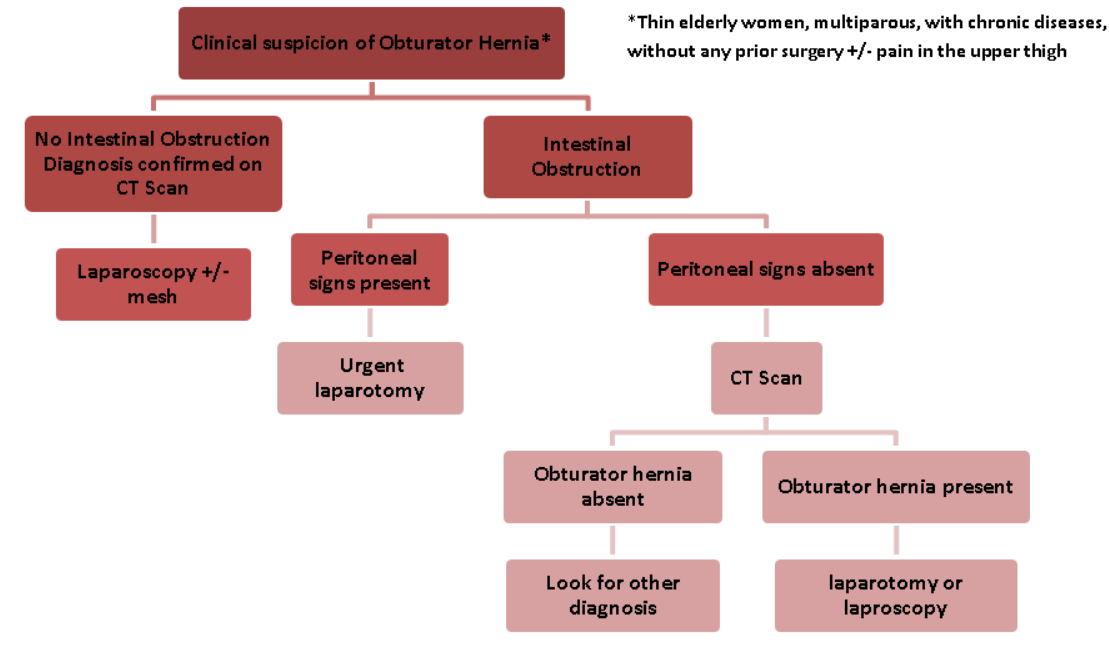

